\title{
Successful Treatment of Pulmonary Edema Caused by Transurethral Resection of the Prostate Syndrome
}

\author{
Hung Tong Xuan \\ Trang Dinh Thi Thu \\ Dinh Ngo Van (D) \\ Ly Nguyen Minh (D)
}

Department of Anesthesiology and Pain Medicine - 108 Military Central Hospital, Hanoi, Vietnam
Correspondence: Ly Nguyen Minh

No. I Tran Hung Dao Street, Hai Ba

Trung District, Ha Noi City, 100000,

Vietnam

Tel +84983496598

Email nmly108@gmail.com
Background: Transurethral resection of the prostate (TURP) syndrome is a complication of transurethral resection of the prostate procedure. The incidence of TURP syndrome ranges from $0.78 \%$ to $1.4 \%$. This syndrome is caused by excessive absorption of electrolyte-free and hypotonic washing solution. The fluids absorb into the circulation, which leads to heart failure, hyponatremia, and a decrease in serum osmolality. Cerebral edema, coma, pulmonary edema, cardiovascular collapse, and even death are common complications.

Case Presentation: We report a patient who suffered severe TURP syndrome after transurethral resection of the prostate procedure. Clinical manifestations were pulmonary edema and respiratory failure. The concentration of $\mathrm{Na}^{+}$was $112.6 \mathrm{mmol} / \mathrm{l}$, which was severe hyponatremia. The serum osmolality pressure was $234 \mathrm{mOsmol} / \mathrm{kg}, \mathrm{pH}$ was $7.23, \mathrm{pO}_{2}$ was $45 \mathrm{mmHg}$ and $\mathrm{pCO}_{2}$ was $44 \mathrm{mmHg}$. The patient had successfully recovered after being used CPAP-PSV Pro breathing through a mask with $+5 \mathrm{cmH}_{2} \mathrm{O}$ of PEEP, $8 \mathrm{cmH}_{2} \mathrm{O}$ of supporting pressure, $70-100 \%$ of $\mathrm{FiO}_{2}, 20 \mathrm{mg}$ furosemide of intravenously, $150 \mathrm{~mL}$ of $3 \% \mathrm{NaCl}$, and $100 \mathrm{~mL}$ natribicarbonate $8.4 \%$.

Conclusion: TURP syndrome is a life-threatening complication of transurethral resection of the prostate procedure, which is caused by excessive absorption of electrolyte-free and hypotonic washing solution. Therefore, the patient should be monitored seriously, diagnosed early, and treated promptly.

Keywords: transurethral resection of the prostate syndrome, prostate tumours, pulmonary edema

\section{Introduction}

Endoscopic syndrome or TURP (transurethral resection of a prostate syndrome (TURP)) syndrome is an undesirable effect of prostatectomy through the urethra. The reason is that the lavage used in endoscopy is hypotonic fluid, without electrolytes absorbed into the lumen through the prostate venous sinuses, changing the circulating volume, disturbing the water balance of electrolytes, especially hyponatremia, and reducing serum osmolality, affecting on the cardiovascular system, respiratory and nervous system. ${ }^{1}$ Symptoms of TURP are often irregular, asynchronous, and nonspecific. Sometimes life-threatening complications such as sudden coma, heart failure, cardiovascular collapse and, respiratory failure ${ }^{2,3}$ are reported. Recent studies show that the incidence of TURP ranges from $0.78 \%$ to $1.4 \%$. Although there are not many severe cases of TURP, the mortality rate is up to $25 \%{ }^{4,5}$ 
There is a case of TURP reported to be severe after a prostatectomy procedure. The male patient is 57 years old, $1.68 \mathrm{~m}$ tall, and weighs $60 \mathrm{~kg}$. He has a history of type II diabetes, no history of cardiovascular disease, and is admitted to the hospital with a diagnosis of benign linear hypertrophy causing dysuria. Therefore, surgery to remove the prostate gland through the urethra is indicated. Before the surgery, the patient was awake, well exposed, selfbreathing at 14 times/minute, $\mathrm{SpO}_{2} 98 \%$. The sound of both sides of the lung is normal, with no rales. Heart rate is 84 cycles/minute, and blood pressure is $132 / 76 \mathrm{mmHg}$. Blood test shows that red blood cell count: $4.63 \mathrm{~T} / \mathrm{L}$, hemoglobin: $148 \mathrm{~g} / \mathrm{L}$, hematocrit: $0.43 \mathrm{~L} / \mathrm{L}$, platelet count: $266 \mathrm{G} / \mathrm{L}$; glucose: $7.8 \mathrm{mmol} / \mathrm{L}$; urea: $6.9 \mathrm{mmol} / \mathrm{L}$; creatinine: $90.6 \mu \mathrm{mol} / \mathrm{L}$; GOT: 20U/L, GPT: $34 \mathrm{U} / \mathrm{L}, \mathrm{Na}^{+}$ concentration: $138 \mathrm{mmol} / \mathrm{L} ; \mathrm{K}^{+}: 3.6 \mathrm{mmol} / \mathrm{L} ; \mathrm{Cl}^{-}: 101$ $\mathrm{mmol} / \mathrm{L} ; \mathrm{Ca}^{2+} 2.17 \mathrm{mmol} / \mathrm{L}$. The results of the electrocardiogram, echocardiography, and cardiopulmonary X-ray are normal. The prostate is measured to be about $35 \mathrm{~g}$ by using ultrasound.

In the operating room, the patient has placed an $18 \mathrm{G}$ needle intravenous line, using $0.9 \%$ natriclorid infusion at the rate of 30 drops/minute. The patient has received oxygen through a nasal catheter at the rate of 3 litres/ minute. A mixture of $8 \mathrm{mg}$ high-density bupivacaine and $0.02 \mathrm{mg}$ fentanyl is used for spinal anaesthesia at the L2-L3 joint. Prostate surgery is procedured by using a monopole burner with about 25 litres of 3\% sorbitol solution. During the surgery, hemodynamic is stable Heart rate is from 70 to 90 cycles/minute, blood pressure ranges from 110/65 to $140 / 80 \mathrm{mmHg}$, breathing rate is from 14 to 15 times/ minute, and the value of $\mathrm{SpO}_{2}$ is from $98 \%$ to $99 \%$. The sheath of the prostate is tearing, which causes losing about $100 \mathrm{~mL}$ of blood. The surgical time is 40 minutes. At the end of the surgery, the patient is awake, well exposed, selfbreathing at 15 times/minute. The value of $\mathrm{SpO}_{2}$ is $97 \%$, heart rate is $71 \mathrm{cycles} / \mathrm{min}$, and blood pressure is $125 / 68$ mmHg.

After 10 minutes of the surgery, the patient is conscious and responsive, sweating, headache, nausea, shortness of breath, self-breathing at 25-28 times/minute, coughing up blood (classically seen as pink). The value of $\mathrm{SpO}_{2}$ is from $75 \%$ to $80 \%$. The sound of alveoli is better, and there are some rales scattered on both sides of the lung. Heart rate is 120 cycles/minute, and blood pressure is $154 / 96 \mathrm{mmHg}$. The arterial blood gas test shows that the value of $\mathrm{pH}$ is 7.23 , the value of $\mathrm{pO}_{2}$ is $45 \mathrm{mmHg}$, the value of $\mathrm{pCO}_{2}$ is $44 \mathrm{mmHg}, \mathrm{Na}^{+}$concentration is 112.6

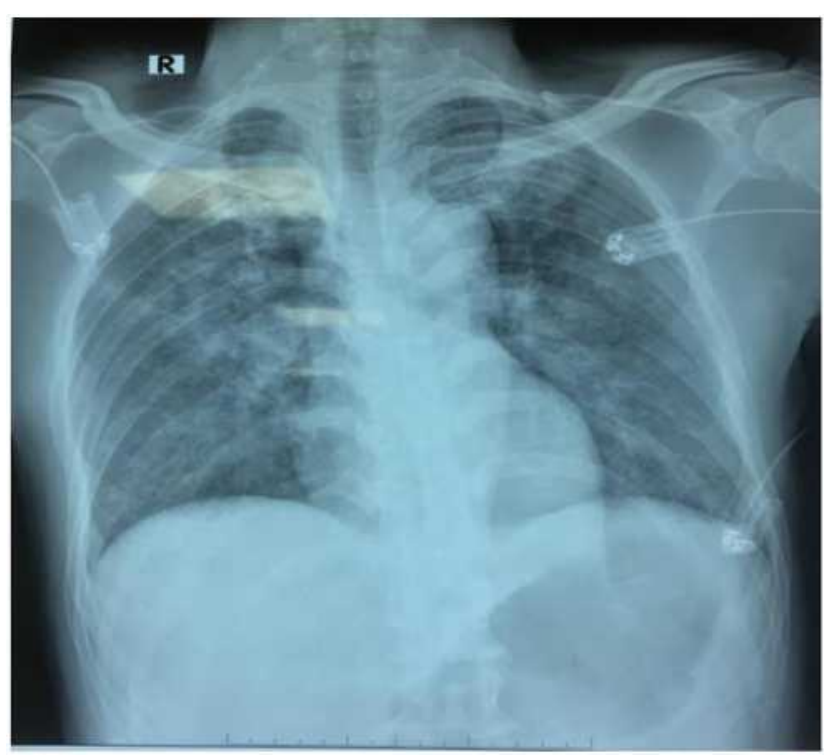

Figure I X-ray image of the patient's lung immediately after 10 minutes of the surgery.

$\mathrm{mmol} / \mathrm{L}, \mathrm{Ka}^{+}$concentration is $2.9 \mathrm{mmol} / \mathrm{L}, \mathrm{Cl}^{-}$: concentration is $80 \mathrm{mmol} / \mathrm{L}$, and the serum osmolality pressure is $234 \mathrm{mOsmol} / \mathrm{kg}$. After 10 minutes of the surgery, there is a heterogeneous fuzzy image on both sides of the lung via a chest X-ray (Figure 1).

Management: Put the patient in fowler position, breathe CPAP-PSV Pro mode through a mask with PEEP $+5 \mathrm{cmH}_{2} \mathrm{O},+8 \mathrm{cmH}_{2} \mathrm{O}$ support pressure, $\mathrm{FiO}_{2} 80 \% ; 20 \mathrm{mg}$ furosemide of intravenously, $150 \mathrm{~mL}$ of $3 \% \mathrm{NaCl}$ in 3 hours, $100 \mathrm{~mL}$ of $8.4 \%$ natribicarbonate; $1 \mathrm{~g} \mathrm{KCl}$ and $1 \mathrm{~g}$ $\mathrm{CaCl}$ of intravenous infusion.

After 3 hours, the patient's condition improves well: awake, good contact, stop nausea, vomiting, breathing better at 18 times/min with 4 liters/min of oxygen. The value of $\mathrm{SpO}_{2}$ is $97 \%$; heart rate is 90 cycles/minute, and blood pressure is $130 / 85 \mathrm{mmHg}$. The arterial blood gas test shows that the value of $\mathrm{pH}$ is 7.40 , the value of $\mathrm{pO}_{2}$ is $72.8 \mathrm{mmHg}$, the value of $\mathrm{pCO}_{2}$ is $37 \mathrm{mmHg}, \mathrm{Na}^{+}$concentration is $125 \mathrm{mmol} / \mathrm{L}, \mathrm{Ka}^{+}$concentration is $2.9 \mathrm{mmol} /$ $\mathrm{L}, \mathrm{Cl}^{+}$concentration is $92 \mathrm{mmol} / \mathrm{L}$, and the serum osmolality pressure is $268 \mathrm{mOsmol} / \mathrm{kg}$. The patient is transferred to the resuscitation department to monitor and treat promptly. After 12 hours of surgery, the arterial blood gas test shows that the value of $\mathrm{pH}$ is 7.40, the value of $\mathrm{pO}_{2}$ is $175 \mathrm{mmHg}$, the value of $\mathrm{pCO}_{2}$ is 44 $\mathrm{mmHg}, \mathrm{Na}^{+}$concentration is $131 \mathrm{mmol} / \mathrm{L}$, and $\mathrm{Ka}^{+}$concentration is $4.3 \mathrm{mmol} / \mathrm{L}$. The patient is transferred to the urology surgery department and was discharged after 7 days of treatment. 


\section{Discussion}

In transurethral resection of the prostate, it is necessary to continuously use bladder wash solution in one way to stretch the bladder to create a surgical field. At the same time, the fluid affects on cleaning blood and tissue so that the operator has good observation during the surgery. ${ }^{5}$ In order to use monopole burner in transurethral resection, the ideal wash solution must be transparent, isotonic to serum, non-conductive, non-toxic, and non-hemolytic. When it is absorbed into the lumen, it is not metabolized, rapidly eliminated from the body and easy to sterilize and low cost. $5,7,9,10$ However, there is no type of fluid that meets all of these criteria. The washing solutions used recently, such as sorbitol, mannitol, and glycine, are hypotonic with serum and have no electrolytes. Three percent sorbitol solution used is an isomer of mannitol with 5.3 of $\mathrm{pH}$ (5-7). The chemical formula is $\mathrm{C}_{6} \mathrm{H}_{14} \mathrm{O}_{6}$, and osmotic pressure is about $165 \mathrm{mOsm} / \mathrm{L}$.

The transurethral resection of the prostate opens the network of the sinuses and veins of the prostate. Therefore, the washing solution will be directly absorbed into the lumen due to the difference between the bladder's pressure and the lumen's. When the pressure gap is about $1.5 \mathrm{kPa}(10 \mathrm{mmHg})$, the washing solution spills into the lumen. ${ }^{3,11-14}$ The prolonged surgery, the increased pressure difference between the lumen and the bladder, and the prostate's puncture are favorable factors for more and faster absorption of the washing solution into the lumen. $4,5,15$ According to some authors, the speech of washing solution absorbed into the blood vessel is on average of $10-30 \mathrm{~mL} / \mathrm{min}$, and sometimes up to $200 \mathrm{~mL} /$ min in surgery. ${ }^{1,2,6,16,17}$ The washing solution absorbed into the blood vessel will increase the circulating volume. Therefore, if it is absorbed too much quickly, it will cause circulatory overload and increase pulmonary capillary pressure, which leads to acute pulmonary edema. ${ }^{1,4}$

$\mathrm{Na}^{+}$is a primary electrolyte in the extracellular region. Therefore, the concentration of $\mathrm{Na}^{+}$plays a crucial role in forming the osmotic pressure of the serum. The osmotic pressure of the serum regulates the water balance between the intracellular and extracellular regions. The average concentration of $\mathrm{Na}^{+}$ranges from 135 to $145 \mathrm{mmol} / \mathrm{L}$. The intracellular and extracellular osmotic pressures are equal and range from 280 to $290 \mathrm{mOsmol} / \mathrm{kg} \mathrm{H}_{2} \mathrm{O}$. When this equilibrium is broken, water is redistributed between the intracellular and extracellular region to restore the balance of the osmotic pressure. The hypotonic washing solution without electrolytes absorbed into the vascular lumen dilutes and reduces the concentration of $\mathrm{Na}^{+}$and the osmotic pressure of the serum. Because of that, the water in the lumen moves to the interstitial space and into the cells, causing brain edema and increased the pressure of the lung's interstitial, which leads to pulmonary edema.

In conclusion, with the clinical manifestations, our patient' blood test results are entirely consistent with the endoscopic syndrome's cause and pathogenesis. It is a severe endoscopic syndrome, with the complications of cerebral edema and pulmonary edema, which causes acute respiratory failure due to hemodynamic, severe reduction of $\mathrm{Na}^{+}$concentration, and decreased osmotic pressure of the serum.

Management of the endoscopic syndrome depends on the severity and clinical manifestations. The patient's test results are assessed on some essential criteria such as good respiratory and hemodynamic control, correction of water disturbances, electrolytes, and acid-base balance. Moreover, if the surgery ends as soon as possible, the washing solution does not continue to be absorbed into the blood. $^{3-5}$ If there are some complications such as cerebral edema, increased intracranial pressure, and acute pulmonary edema, the diuretics furosemide is indicated on the hemodynamic stability. Because hypertonic saline serum has an effect on increasing extracellular fluid tonicity, which makes water move from intracellular to the extracellular region, $3 \%$ hypertonic $\mathrm{NaCl}$ is infused to regulate the concentration of $\mathrm{Na}^{+}$and to prevent the intercellular edema, cerebral edema, and pulmonary edema. The authors suggest that when the concentration of $\mathrm{Na}^{+}$is less than $120 \mathrm{mmol} / \mathrm{L}$ or there are some severe endoscopic syndrome such as severe headache, prolonged nausea, and vomiting, convulsions and, coma, the hypertonic saline serum is indicated to use. The main purpose of regulating the concentration of $\mathrm{Na}^{+}$is to improve clinical symptoms, which is not to bring the concentration of $\mathrm{Na}^{+}$to the normal value. Adjusting the concentration of $\mathrm{Na}^{+}$less than $1 \mathrm{mmol} / \mathrm{L}$ per hour aims to avoid damage to the central nervous system caused by the destruction of myelin. ${ }^{4,5}$

Olson J. (2011) reported a case of severe endoscopic syndrome. ${ }^{6}$ After 30 minutes of the prostate surgery, the 81-year-old patient appeared a change of consciousness and went into a coma. Then, his heart stopped. After being resuscitated, the heart beat again. The test found that the concentration of $\mathrm{Na}^{+}$was $114 \mathrm{mmol} / \mathrm{L}$, which significantly reduced compared to the result before the surgery (145 mmol/L). Cardiopulmonary X-ray's result showed lesion on both sides of the lung. ${ }^{6}$ 
Vinay Kumar (2019) also reported that right after the prostate surgery, an 80-year-old patient had appeared endoscopic syndrome with symptoms of hypertension, slow heart rate, confusion, and hypoxemia. ${ }^{8}$ The concentration of $\mathrm{Na}^{+}$ dropped to $120.6 \mathrm{mmol} / \mathrm{L}$, the concentration of $\mathrm{K}^{+}$went up to $6.48 \mathrm{mmol} / \mathrm{L}$, and the amount of washing solution absorbed was measured about 3 litres. Because the patient was diagnosed and treated early, he made a complete recovery. ${ }^{8}$

In our case, cerebral edema and pulmonary edema are major complications which cause respiratory failure. Pulse and blood pressure are in the permission limits, so we manage to put the patient in fowler position, to support the patient's breathing with a CPAP-PSV Pro via a face mask with PEEP $+5 \mathrm{cmH}_{2} \mathrm{O}, 8 \mathrm{cmH}_{2} \mathrm{O}$ of pressure, $70-100 \% \mathrm{FiO}_{2}, 20 \mathrm{mg}$ furosemide of intravenously, $150 \mathrm{~mL}$ of $3 \% \mathrm{NaCl}$ infusion at the speech of 50 drops $/ \mathrm{min}$ and $100 \mathrm{~mL}$ of $8.4 \%$ natribicarbonate to balance acid-alkaline electrolyte. After 3 hours of treatment, the clinical condition improves significantly: stop nausea, vomiting and breathing better at 16-18 times/minute. The value of $\mathrm{SpO}_{2}$ is $98 \%$, heart rate is 90 cycles/ minute, and blood pressure is $130 / 85 \mathrm{mmHg}$. The value of $\mathrm{pH}$ is 7.40 , the value of $\mathrm{pO}_{2}$ is $72.8 \mathrm{mmHg}$, the value of $\mathrm{pCO}_{2}$ is $37 \mathrm{mmHg}, \mathrm{Na}^{+}$concentration is $125 \mathrm{mmol} / \mathrm{L}$, the serum osmolality pressure is $268 \mathrm{mOsmol} / \mathrm{kg}$. After 24 hours, the patient recovers completely.

\section{Conclusion}

A severe endoscopic syndrome is an undesirable effect in the prostate surgery when using hypotonic and non-electrolyte washing solution, which could threaten the patient's life. Therefore, the patient should be monitored seriously and treated promptly with appropriate management.

\section{Ethics Approval and Consent to Participate}

The case reports received approval for publication from the Ethics Committee of 108 Military Central Hospital.

\section{Consent for Publication}

Written informed consent for publication of the clinical details and clinical images was obtained from the patient.

\section{Disclosure}

The authors report no conflicts of interest in this work.

\section{References}

1. Gravenstein D. Transurethral resection of the prostate (TURP) syndrome: a review of the pathophysiology and management. Anesth Analg. 1997;84:438-446. doi:10.1213/00000539-199702000-00037

2. Gupta K, Rastogi B, Jain M, et al. Electrolyte changes: an indirect method to assess irrigation fluid absorption complications during transurethral resection of prostate: a prospective study. Saudi $J$ Anaesth. 2010;4(3):142-146. doi:10.4103/1658-354X.71505

3. Hahn RG. Fluid absorption in endoscopic surgery. $\mathrm{Br} J$ Anaesth. 2006;96:8-20. doi:10.1093/bja/aei279

4. Hawary A, Mukhtar K, Sinclair A, et al. Transurethral resection of the prostate syndrome: almost gone but not forgotten. $J$ Endourol. 2009;23(12):2013-2020. doi:10.1089/end.2009.0129

5. O'Donnell AM, Foo IT. "Anaesthesia for transurethral resection of the prostate", continuing education in anaesthesia. Crit Care Pain. 2009;9(3/2009):92-96.

6. Olson J, Peters S. Pulmonary edema and cardiac arrest complicating transurethral resection of the prostate and TURP syndrome. Chest. 2011;140(4):140-152. doi:10.1378/chest.1114237

7. Salma AG, Khalid AG, Ahmed NG. Volumetric overload shocks in the patho-aetiology of the transurethral resection of the prostate (Turp) syndrome and acute dilution hyponatraemia: the clinical evidence based on prospective clinical study of 100 consecutive Turp. Biomed Res Clin Pract. 2017;2(3):1-7.

8. Kumar V, Vieet K, Deb A. TUR syndrome - a report. Urol Case Rep. 2019;26(2019):1-2.

9. Collins JW, Macdermott S, Brad RA, Keely FX, Timoney AG. The effects of the choice of irrigating fluid on cardiac stress during transurethral resection of the prostate: a comparison between $1.5 \%$ glycine and 5\% glucose. $J$ Urol. 2007;177:1369-1373. doi:10.1016/j. juro.2006.11.042

10. Imiak S, Weavind L, Dabney T, Wenker O. TURP syndrome interactive case report in anesthesia and critical care. Int J Anesthesiol. 1999;3:1.

11. Henderson DJ, Middleton RG. Coma from hyponatremia following transurethral resection of the prostate. Urology. 1980;15:267-271. doi:10.1016/0090-4295(80)90441-0

12. Boukatta B, Sbai H, Messaoudi F, Lafrayiji Z, Bouazzaoui AE, Kanjaa N. Transurethral resection of prostate syndrome: report of a case. Pan Afr Med J. 2013;14(1).

13. Tolksdorf W, Goetz D, Peters HJ, Potempa J, Lutz H. Infusion therapy during transurethral prostatectomy. Infusionsther Klin Ernahr. 1980;7:148-154.

14. Yousef A, Suliman G, Elashry O, Elshorahy M, Elgamasy A. A randomized comparison between three types of irrigating fluids during transurethral resection in benign prostatic hyperplasia. $B M C$ Anesthesiol. 2010;10(7). doi:10.1186/1471-2253-10-7

15. Harrison RH III, Boren JS, Robinson JR. Dilutional hyponatremic shock: another concept of the transurethral prostatic resection reaction. $J$ Urol. 1956;75:95-110. doi:10.1016/S0022-5347(17) 66783-1

16. Robert G, Hahn MD. Transurethral resection syndrome after transurethral resection of bladder tumours. Can J Anaesth. 1995;42 (1):69-72. doi:10.1007/BF03010574

17. Reich O, Gratzke C, Bachmann A, et al. Morbidity, mortality and early outcome of transurethral resection of the prostate: a prospective multicenter evaluation of 10654 patients. $J$ Urol. 2008;180 (1):246-249. doi:10.1016/j.juro.2008.03.058 


\section{Publish your work in this journal}

Research and Reports in Urology is an international, peer-reviewed, open access journal publishing original research, reports, editorials, reviews and commentaries on all aspects of adult and pediatric urology in the clinic and laboratory including the following topics: Pathology, pathophysiology of urological disease; Investigation and treatment of urological disease; Pharmacology of drugs used for the treatment of urological disease. The manuscript management system is completely online and includes a very quick and fair peer-review system, which is all easy to use. Visit http://www.dovepress.com/ testimonials.php to read real quotes from published authors. 